\title{
A LINGUISTIC COORDINATOR
}

\author{
by Constance Reid
}

The ideas expressed in this article were prompted by a proposal made at the meeting of the NALLD in New York City during the 1968 Northeast Conference. This proposal us one dealing with the establisbment of graduate programs to train language laboratory directors.

Essentially, these ideas revolve around those expressed by Dr. Karl S. Pond in bis addless to the Association in Atlantic City in April, 1967. Here be conceived of the role of the language laboratory director as that of a coordinator of courses in all languages-at least in courses at the beginning levels of instruction where the emphasis is on language acquisition. For the purposes of this article such an individual might be termed a linguistic coordinator, since the laboratory and the classroom which be is to coordinate should work mutually to achieve the objective of linguistic acquisition.

The concept of linguistic coordinator has validity not only from a theoretical and pedagogical standpoint, but from a practical one as well; for often the position of language laboratory director cannot be a full time one. High schools, junior high schools and small colleges-in other words, those institutions which are responsible for the foreign language training of the majority of our students-usually cannot afford to have a full-time laboratory director and whatever alternative arrangements may be made to deal with this fact are likely to turn out to be unsatisfactory. In fact, there have been instances in which it would have been better to have no laboratory at all than one administered by a part-time director. This is not to say that the director himself was in any way at fault; it is to say that the situation unavoidably makes for many extra difficulties.

Whereas the position of language laboratory director often cannot be a full-time one, that of coordinator of beginning foreign language courses can be, since the former more or less separate functions of parttime language laboratory director on the one hand and of classroom instructor on the other hand still occupy the professional's time and attention. However, they do so in a more streamlined, integrated and perhaps different fashion than previously.

The integration and coordination involved here are related to Professor Pond's thesis that the language laboratory director should be 
trained in the psychology of learning and learning theories, linguisticsincluding applied linguistics-and general methodology. Such training would not only prepare an individual for his task of coordinating the initial levels of courses in the various languages with the laboratory and, it might be added, with each other where possible, but it would also enable him to make explicit application of his knowledge in these areas in his teaching schedule. For a college instructor this would mean that he might teach a course in foreign language methodology, in general linguistics-a course which would service non-language majors as well as language majors, or in applied linguistics. For an educator on the high school or junior high school level this would mean that he might teach classes involving in-service training, an activity which is becoming increasingly prominent and prevalent in the educational picture. In the instance of either the grade school or the college instructor, it would probably be the case that he would continue, as traditionally, to teach at least one actual language course. The desirability of this cannot be stressed enough; the linguistic coordinator should always maintain contact with the classroom and its processes.

The number of courses taught by a linguistic coordinator should be determined as a result of first ascertaining how much time is needed for his primary function of supervising the language laboratory and coordinating language courses with it. Naturally this will depend on the local situation, but in no case should less than one-fourth of his time be allotted for the execution of his primary function. Such an allotment would be minimal.

A hypothetical schedule for a linguistic coordinator in a small college on the semester system might be as follows: half time devoted to course coordination and supervision of the language laboratory, including overseeing student laboratory assistants; teaching course in foreign language methodology, first semester; teaching a course in general linguistics, second semester; and teaching a full-year course in a language at either the elementary or the intermediate level. This hypothetical schedule corresponds to the average load of four courses per semester where one course counts three semester hours.

Above, it has been asserted that a primary function of the linguistic coordinator is to coordinate language courses with the laboratory. This function needs to be elaborated upon since it embodies the essence of the task of the linguistic coordinator. First it must be made clear that a linguistic coordinator does not replace the traditional language department chairman or head, although in a system where few language courses are offered the two could possibly be one and the same. The linguistic coordinator cuts across departmental boundaries, if there are 
such; he does not head the French Department, the Russian Department, or even the Modern Language Department. He does not have jurisdiction over upper-level literature courses as does the department chairman. Rather, it is his goal to see that students are linguistically prepared for advanced language courses. The linguistic coordinator is a specialist who understands the best and most recent developments in the field of foreign language pedagogy. Based on this knowledge, he can, in cooperation with the language chairman or chairmen and the language staff, set the objectives of foreign language courses and then establish the step-by-step procedures through which these objectives are to be attained within various courses. Finally, he can cooperate with his fellow educators in seeing that the desired and agreed upon objective will be achieved.

The above description of the function of the linguistic coordinator now leads us to return to the proposal which promoted the description, that of the establishment of graduate programs for the training of language laboratory directors. Such programs should include courses and seminars which would enable the student to perform the functions of the linguistic coordinator. That is, in addition to receiving training for the technical and administrative demands normally associated with the position of language laboratory director, he should receive training in foreign language methodology and teacher training, general and applied linguistics, and the psychology of learning and of language. It is assumed that he be fluent in at least one foreign language and especially desirable that he know more than this. For, even if he does not teach more than one language, such knowledge will go a long way in equipping him to act as a much needed integrative force in the foreign language field. By the very nature of his duties, the linguistic coordinator is in a position to act as such a force.

(It should be noted that the concept of linguistic coordinator is not entirely theoretical. There are at present individuals who could be referred to as linguistic coordinators in accordance with the above description. The language programs with which they are associated have produced students who are well trained linguistically.) 